\title{
VIOLACIONES AL DEBIDO PROCESO EN EL PROCEDIMIENTO ADMINISTRATIVO POR CONTRIBUCIONES OMITIDAS. UN ANÁLISIS A LUZ DE LOS DERECHOS HUMANOS
}

\section{Gabriela AGUADO ROMERO*}

\begin{abstract}
Sumario
I. Introducción II. Actos de comprobación de la autoridad aduanera III. La revisión de documentos para el despacho aduanero IV. El reconocimiento aduanero $V$. La verificación de mercancías en transporte VI. El Procedimiento Administrativo en Materia Aduanera (PAMA) VII. El Procedimiento Administrativo por Contribuciones Omitidas (PACO) VIII. El debido proceso IX. Protección internacional al debido proceso X. Conclusiones XI. Fuentes
\end{abstract}

\begin{abstract}
Resumen. Dentro del presente trabajo se realiza el análisis del procedimiento administrativo por contribuciones omitidas que prevé el artículo 152 de la Ley Aduanera, para demostrar que este procedimiento vulnera el derecho humano al debido proceso, previsto tanto en la Constitución Mexicana como en el derecho internacional de los derechos humanos. Esta violación se presenta cuando se soslaya el principio de legalidad, otorgando con esto un margen de discrecionalidad a favor de la autoridad aduanal en contra de la figura del contribuyente. Con lo anterior, se observa una falta de armonización para la protección de los derechos humanos ya que, a pesar de que la reforma constitucional de 2011 en materia de derechos humanos trae aparejada un cambio en la forma de interpretar la Constitución y los tratados internacionales de los que el Estado Mexicano sea parte, es evidente que la legislación secundaria aduanal obstaculiza el cumplimiento de este fin.
\end{abstract}

Palabras clave. Debido proceso; derecho internacional; derechos humanos; constitución; procedimiento administrativo por contribuciones omitidas.

Keywords: Due process; international law; human rights; constitution; administrative procedure for omitted taxes

\section{Introducción}

En cada ámbito de la vida cotidiana están implicados con menor o mayor inferencia los actos jurídicos, sin embargo, no analizamos los aspectos legales detrás de estos, solamente realizamos

\footnotetext{
* Doctora en Derecho por la Universidad Autónoma de Querétaro, México. Profesora e investigadora de tiempo completo de la Facultad de Derecho (UAQ), con Reconocimiento Perfil Deseable PRODEP, integrante del Cuerpo Académico Consolidado "Derechos humanos y globalización" Facultad de Derecho (UAQ), miembro del Sistema Nacional de Investigadores del Consejo Nacional de Ciencia y Tecnología. ORCID: https://orcid. org/oooo-0003-3733-6459 Contacto: aguadogabriela@hotmail.com.
} 
tal deconstrucción de los actos intrincados en las relaciones de la vida cotidiana hasta que uno afecta de manera relevante nuestros derechos, es entonces cuando estas acciones se visibilizan.

Por tanto, es necesario hacer un reconocimiento de derechos fundamentales dentro de los procedimientos legales que se siguen por todo el mundo, principios básicos que no deben ser vulnerados, pero, sobre todo, que deben ser vigilados y promovidos. Los derechos humanos, entendidos como prerrogativas esenciales del trato entre iguales, han evolucionado a lo largo del tiempo, de tal forma que hoy en día se encuentra el derecho humano al debido proceso.

Anteriormente esta garantía estaba dirigida principalmente al proceso judicial; posteriormente, fue reconocida en los procedimientos administrativosi, donde su cumplimiento en el desarrollo de procedimientos legales es obligatorio. Dichas prerrogativas fundamentales son de una gran observancia e importancia, al grado que diferentes mecanismos internacionales, nacionales e incluso doctrinales las reconocen.

La reforma constitucional del 10 de junio de 2011 en materia de derechos humanos, en donde se cambia el título primero, capítulo primero, que anteriormente se denominaba: De las Garantías Individuales, por la denominación actual que es: De los Derechos Humanos y sus Garantías, trae como consecuencia diversos cambios en la forma de interpretar la Constitución y, por consecuencia, en la forma de interpretar cualquier ordenamiento en México, creando una línea horizontal con todos estos en sus diferentes materias.

La incorporación de los derechos humanos en la Constitución Mexicana vuelve obligatorio el respetar y seguir las pautas del debido proceso dentro de los procedimientos que se llevan a cabo en nuestro país, lo cual se advierte en el contenido del artículo primero constitucional, el cual establece una protección amplia de los derechos humanos, entre estos, el de debido proceso.

Mediante el reconocimiento claro del principio pro personae, se brinda mayor protección al aplicar aquellas normas jurídicas que más favorezcan, sosteniendo que debe tenerse en cuenta esencialmente lo justo, es decir, que prevalezca la situación imparcial y razonable antes que las normas organizadas en sistema. Nos encontramos dentro de un proceso jurídico globalizador:

Un sistema universal sobre los sistemas regionales, esto implica una evolución gradual de la figura del Estado en aras de un avance progresivo hacia la construcción de una comunidad mundial, en donde la observancia de los derechos humanos se encuentra protegida por un control internacional que atraviesa las fronteras de los Estados, buscando el cumplimiento de fines y valores universales. La tradición humanística común debe ser el lugar donde confluyan las tendencias opuestas de los Estados respecto a los derechos humanos ${ }^{2}$.

Sin embargo, el derecho humano al debido proceso lejos de ser respetado es común que sea violentado. Un caso específico de su inobservancia y por lo tanto vulneración al derecho humano, es el que se da en el Procedimiento Administrativo por Contribuciones Omitidas (PACO), ya que, al estar en vigor diferentes ordenamientos jurídicos que facultan el actuar de las autoridades, como lo son la Ley Aduanera Mexicana, el Código Fiscal de la Federación, el Manual de

\footnotetext{
${ }^{1}$ En el proceso judicial se reconocía dicha garantía desde 1215, mientras que en el procedimiento administrativo no es sino hasta 1615, en el caso Bagg, cuando un habitante de Plymouth fue sancionado por el alcalde sin ser escuchado y los tribunales sostuvieron que la sanción era nula porque al afectado no se le concedió una audiencia previa. Véase Hoyos, Arturo (2006), Debido proceso y democracia, México, Porrúa, p. 148.

2 Aguado Romero, Gabriela, et al. (2016), "Un espacio judicial para una teoría naturalizada de los derechos humanos”, en Derecho administrativo. Un ámbito para el respeto, promoción, protección y garantía de los derechos humanos, México, Tirant lo Blanch, p. 47.
} 
Operación Aduanera, el Reglamento Interior del Servicio de Administración Tributaria, entre otros, podemos observar que, al hacer un análisis de su contenido, queda de manifiesto una falta de delimitación clara y específica de las facultades de la autoridad. Pero también ocurre que estando especificadas de manera clara y precisa las facultades en la Ley de la materia, éstas extralimitan los parámetros de observancia constitucional e internacional del debido proceso. Es de explorado derecho, que todas las actuaciones de las autoridades deben estar regidas por las normativas jurídicas que le son aplicables a fin de calificarse de legales ${ }^{3}$. Con esto podemos afirmar que no siempre el ordenamiento positivo contempla en sus contenidos los principios del derecho natural que son acordes y propios de la naturaleza humana.

Ante un positivismo tan extendido y cerrado como es el caso de nuestro ordenamiento jurídico mexicano, y ante un exceso legislativo que antes de evitar los conflictos y las situaciones problemáticas en nuestro país complica más la tarea de darles solución ${ }^{4}$, se contrapone el hecho de que pocas veces los derechos humanos han sido de tal modo proclamados como lo vemos en las sociedades actuales. Los derechos humanos tienen origen y fundamento en el hombre mismo, son esenciales, derivados de la dignidad inherente a la persona.

Si retomamos el tema central del presente estudio, podemos precisar que el problema a tratar es cómo se vulnera de manera grave la esfera jurídica del gobernado cuando se conceden facultades discrecionales a las autoridades aduaneras, dejando completamente de lado el principio de legalidad así como el derecho humano al debido proceso. Se hace necesario un análisis sobre estos actos jurídicos de afectación directa en la esfera jurídica de la persona, las implicaciones legales que conlleva, la fundamentación y motivación de la autoridad para llevarlos a cabo.

Por lo tanto, se empleará una metodología exegética; también se hará uso de la técnica documental, bibliográfica específicamente; se realiza una revisión doctrinal que da lugar a un considerable marco teórico. Al aplicar esta metodología y técnica perseguimos describir, pero también explicar los hechos. Primero, se realiza un análisis de algunos de los actos de comprobación de la autoridad aduanera y del procedimiento administrativo en materia aduanera como estudio previo a nuestro tema central que es el análisis del procedimiento administrativo por contribuciones omitidas que prevé el artículo 152 de la Ley Aduanera, en donde observamos evidentes violaciones a los derechos del gobernado. Posteriormente, se realiza un estudio de los antecedentes y fundamento del debido proceso para terminar proponiendo una observancia del derecho humano al debido proceso en los ordenamientos que regulan el procedimiento en materia aduanera, confome a la regulación constitucional e internacional de los derechos humanos.

\section{Actos de comprobación de la autoridad aduanera}

Los actos de comprobación de la autoridad aduanera encuentran su base legal en la Constitución Mexicana en el Código Fiscal de la Federación, en la Ley Aduanera y el Reglamento del Servicio de Administración Tributaria. La actuación de la autoridad aduanera precisa de diferentes formas de comprobación fiscal en donde las autoridades ejercen facultades, entre éstas tenemos:

\footnotetext{
${ }^{3}$ Bello, Nohemí y Avendaño, Luis (2015), "La garantía de audiencia en algunos procedimientos aduaneros”, Letras Jurídicas, Veracruz - México, Año 16, No. 31, enero - junio, p. 32.

${ }^{4}$ Véase, "Un espacio judicial para una teoría naturalizada de los derechos humanos", en la obra de AGUADo Romero, Gabriela et al. (2016), Derecho administrativo. Un ámbito para el respeto, promoción, protección y garantía de los derechos humanos, México, Tirant lo Blanch, pp. 61-63.
} 
1. El reconocimiento aduanero y segundo reconocimiento

2. Las visitas domiciliarias

3. La verificación de mercancías en transporte

4. La retención de mercancías de comercio exterior

5. La glosa de documentos

6. Las visitas de inspección

Dentro de la actividad de comercio exterior se contemplan numerosos procesos y procedimientos que aluden a la responsabilidad de quien importa o exporta y a la verificación de las mercancías. Para el caso de que la autoridad, tras haber ejercido su facultad de comprobación a través de alguna de las formas antes enumeradas, tenga conocimiento de alguna irregularidad, este hecho dará lugar a que, de inicio, cualquiera de los siguientes procedimientos de acuerdo al supuesto:

- El procedimiento administrativo en materia aduanera (PAMA), previsto en los artículos 150, 151 y 153 de la Ley Aduanera

- El procedimiento administrativo por contribuciones omitidas (PACO), previsto en el artículo 152 de la Ley Aduanera

Estos procedimientos siguen una serie de etapas que conllevan consecuencias jurídicas sobre el gobernado. Para el objetivo del presente estudio, nos parece oportuno revisar lo relativo a la revisión de documentos para el despacho aduanero, el reconocimiento aduanero y la verificación de mercancías en transporte, debido a la relación que guardan con el procedimiento administrativo por contribuciones omitidas.

\section{La revisión de documentos para el despacho aduanero}

Quien introduzca o extraiga mercancías del territorio nacional destinándolas a un régimen aduanero tiene por obligación la elaboración de un pedimento referente a las citadas mercancías. Una vez que ha sido validado el pedimento y efectuado el pago de las contribuciones, el interesado debe presentarse ante la aduana para realizar el despacho aduanero. El enorme número y volumen de papeleo que se tenía que presentar para la circulación de las mercancías a través de las fronteras dio lugar a que se realizaran reformas en el ordenamiento aduanero para agilizar el movimiento y despacho de las mercancías.

El servicio de Administración Tributaria (SAT) puso en marcha el programa "Aduana sin papeles", el cual está directamente alineado a los esquemas de facilitación aduanera propuestos por la OMC en la Conferencia Ministerial de Bali efectuada en 2013, y que preveía 5 años antes en México. Dentro de este programa, cuya implementación fue publicada en Reglas Generales de 
Comercio Exterior para 2016, se pretende agilizar los procesos de importación y exportación de mercancías a través de sistemas electrónicos5.

Por lo anterior, es por lo que podemos ver que diferentes disposiciones de la Ley Aduanera refieren la obligación de que quienes introduzcan o extraigan mercancías del territorio nacional para ser destinadas a un régimen aduanero están obligados a transmitir, mediante documento electrónico, a las autoridades aduaneras la información a través del sistema electrónico aduanero, empleando la firma electrónica avanzada, el sello digital u otro medio tecnológico de identificación, en los términos y condiciones que establezca el Servicio de Administración Tributaria mediante reglas, en las que además se podrán determinar los casos en que la información o el trámite deban presentarse a través de medios distintos al electrónico o digital. Pues, como lo dispone el artículo 46 de la Ley Aduanera:

Cuando las autoridades aduaneras con motivo de la revisión de las declaraciones electrónicas efectuadas y de los documentos electrónicos o digitales transmitidos, y presentados ante las mismas; del reconocimiento aduanero; de la inspección o de la verificación de mercancías en transporte, tengan conocimiento de cualquier irregularidad, la misma se hará constar en documento que para el efecto se levante, de conformidad con el procedimiento que corresponda, en los términos de los artículos 150 a 153 de esta Ley.

En el ejercicio de sus facultades de comprobación, la autoridad aduanera realiza la revisión de documentos para el despacho aduanero, y el inicio de alguno de los procedimientos que dispone el ordenamiento de la materia será siempre consecuencia de las irregularidades que la autoridad pueda constatar mediante la revisión.

\section{El reconocimiento aduanero}

Para poder revisar el supuesto de procedimiento administrativo sobre el que versa el presente estudio es necesario analizar el reconocimiento aduanero como escenario previo a la aplicación del procedimiento, en el cual se detectan las irregularidades sancionadas. El examen físico o documental de las mercancías de importación o de exportación en el punto de entrada o de salida es un acto que corresponde realizarlo a las autoridades aduaneras, es lo que se conoce como reconocimiento aduanero. Este es un medio que utiliza la autoridad para tener elementos que le ayuden a determinar la veracidad de lo declarado en los documentos aduaneros.

No siempre ha lugar un reconocimiento aduanero pues, como lo dispone el artículo 43 de la Ley Aduanera, una vez que es elaborado el pedimento y efectuado el pago de las contribuciones y cuotas compensatorias, se deberán presentar las mercancías con el pedimento ante las autoridades aduaneras y activar el mecanismo de selección automatizado que determinará si

\footnotetext{
${ }^{5}$ Rivera Ruiz, Libertad (2019), “Documento de Operación para Despacho Aduanero (DODA)”, Revista Eje de Comercio Exterior. Aduanas, México, [en línea], disponible en: http://aduanasrevista.mx/documento-de-operacion-para-despacho-aduanero-doda/ (consultado el 24 de junio de 2019)

${ }^{6}$ México, Ley Aduanera (2019), artículo 46.
} 
las mercancías estarán sujetas a un reconocimiento aduaneroำ. El mencionado precepto legal señala a la autoridad los pasos a seguir para llevar a cabo el reconocimiento aduanero ${ }^{8}$.

Aunque existen distintos tipos de reconocimiento aduanero, el proceso general que debe seguir el verificador consta de los siguientes pasos:

1. Visualizar en el sistema el número de documento aduanero sujeto a reconocimiento aduanero

2. Realizar la revisión del documento aduanero

3. Inspeccionar físicamente la mercancía

4. Detectar alguna irregularidad

5. Proceder a levantar el acta correspondiente en caso de detectar alguna irregularidad

6. Si la incidencia no merece la retención de la mercancía y el medio de transporte, deberá certificar y liberar el documento aduanero y el medio de transporte ${ }^{9}$

Lo anterior se encuentra previsto en el ya mencionado artículo 46 de la Ley Aduanera. Al respecto y como parte del análisis previo a nuestro objeto de estudio, acercamos esta revisión del Segundo Tribunal Colegiado del Décimo cuarto circuito, en el Amparo directo 123/98, 9 de julio de 1998, que a la letra dispone:

PARTE DE IRREGULARIDADES EN MATERIA ADUANERA. NO CONSTITUYE EL PROCEDIMIENTO IDÓNEO PARA EL EJERCICIO DE FACULTADES DE COMPROBACIÓN. Conforme al artículo 43 de la Ley Aduanera, se encuentra previsto el mecanismo de selección aleatoria para el efecto del reconocimiento de mercancías, lo que constituye el ejercicio de las facultades de comprobación de las autoridades aduaneras; por otra parte, en términos de lo ordenado en el diverso numeral 46 de la misma ley, si con motivo de la revisión de los documentos presentados para el despacho de mercancías del reconocimiento administrativo o del segundo reconocimiento, se advierte alguna irregularidad, las autoridades aduaneras deberán hacerlo constar en un acta circunstanciada, señalando los hechos y omisiones observados, además de asentar las irregularidades que se adviertan del dictamen aduanero; por ello la mera expedición del parte de irregularidades que originó la determinación de una infracción en materia de comercio exterior no constituye un acto de los que conforman el procedimiento previsto en la ley de la materia como sustento del ejercicio de las facultades comprobatorias de las autoridades aduaneras. SEGUNDO TRIBUNAL COLEGIADO DEL DÉCIMO CUARTO CIRCUITO. Amparo directo 123/98. Pedro Manuel Azueta Cárdenas. 9 de julio de 1998. Unanimidad de votos. Ponente: Pablo V. Monroy Gómez. Secretario: José Guadalupe Orta Méndez ${ }^{10}$.

\footnotetext{
7 El reconocimiento podrá ser verde, lo que significa que el dictaminador aduanero solo hará revisión documental del despacho, o rojo, que implica que también hará una inspección de la mercancía.

${ }^{8}$ México, Ley Aduanera (2019), artículo 43.

${ }^{9}$ GrupoEi (2019), Proceso y tipos de reconocimiento aduanero, 4 de diciembre de 2019, [en línea], disponible en: https://blog.grupoei.com.mx/proceso-reconocimiento-aduanero (consultado el 24 de junio de 2019)

${ }^{10}$ 195466. XIV.20.38 A. Tribunales Colegiados de Circuito. Novena Época. Semanario Judicial de la Federación y su Gaceta. Tomo VIII, Octubre de 1998, Pág. 1179.
} 


\section{$V$. La verificacion de mercancías en transporte}

La verificación de las mercancías de comercio exterior en transporte es la revisión que realizan las autoridades fiscales y que consiste en una revisión documental y física de las mercancías que se transportan a través de los tráficos terrestres, marítimos o fluviales, o a través de los vehículos de procedencia extranjera, pudiéndose encontrar estos en circulación o no en la vía o lugares públicos. Las autoridades aduaneras ejercen esta facultad, más comunmente por medio de la verificación, en un punto en carretera, en brechas, o sobre vigilancia o en una volanta fiscal, en la vía o lugares públicos utilizando una orden escrita.

La constancia de identificación es el documento con el que la autoridad aduanera ha de identificarse previamente para poder realizar una verificación de mercancías en transporte, dicha constancia es emitida por el administrador general de aduanas o, en su caso, por el administrador general de la aduana de la circunscripción territorial donde se realiza el acto de comprobación; o en su defecto, por cualquier otro servidor público competente para emitirla.

El fundamento legal de la verificación de mercancías en transporte esta previsto en el artículo 144, fracción XI de la Ley Aduanera que establece que la Secretaría tendrá, además de las conferidas por el Código Fiscal de la Federación y por otras leyes, determinadas facultades, entre estas, la de verificar en forma exclusiva durante su transporte la legal importación o tenencia de mercancías de procedencia extranjera en todo el territorio nacional, incluidos los recintos fiscales, para lo cual podrá apoyarse de los sistemas, equipos tecnológicos, cualquier otro medio o servicio con que se cuente, incluso en el dictamen aduanero a que se refiere el artículo 43 de esta Ley ${ }^{11}$.

\section{El procedimiento administrativo en materia aduanera (PAMA)}

En este apartado revisaremos las características del Procedimento Administrativo en Materia Aduanera (PAMA) que, aunque no es el tema central del presente estudio, nos sirve su análisis para poder diferenciarlo del procedimiento administrativo por contribuciones omitidas y delimitar nuestro objeto de estudio. Se conoce como procedimento administrativo en materia aduanera al que consiste en el conjunto de pasos a seguir ligados de forma sucesiva para que la autoridad, en el ejercicio de sus facultades de comprobación, resuelva condenando o absolviendo respecto a la ilegalidad o legalidad de las mercancías objeto de operaciones de comercio exterior.

La naturaleza jurídica de este procedimiento es la de ser una figura procesal en la que se determina y regula el cómo debe de actuar la autoridad conforme a la norma; hacerlo de otra manera estaría fuera de su ámbito de competencia y de los fines por el que fue creado ${ }^{12}$. El artículo 150 de la Ley aduanera dispone en su primer párrafo:

Las autoridades aduaneras levantarán el acta de inicio del procedimiento administrativo en materia aduanera, cuando con motivo del reconocimiento aduanero, de la verificacion de

\footnotetext{
${ }^{11}$ México, Ley Aduanera (2019), artículo 144, fracción XI.

${ }^{12}$ Cancino, Rodolfo y Askar, Rubén Abdo (2017), El Procedimiento Administrativo en Materia Aduanera. Teoria y Práctica, México, Universidad Tecnológica de Ciudad Juárez, p. 14.
} 
mercancías en transporte o por el ejercicio de las facultades de comprobación, embarguen precautoriamente mercancías en los términos previstos por esta Ley ${ }^{13}$.

El artículo 150 de la Ley Aduanera, siendo el fundamento que le da validez al PAMA, entre otras disposiciones establece que el interesado que ha cometido una infracción, además de señalar testigos y domicilio para recibir notificaciones, cuenta con un plazo de diez días hábiles, contados a partir del día siguiente a aquél en que surta efectos la notificación del acta a fin de ofrecer las pruebas y formular los alegatos que a su derecho convengan, para demostrar aquello que pretenda acreditar, así como la autoridad competente para recibirlas y su domicilio. Dicho plazo se computará conforme lo señalo en el artículo 153 de la Ley Aduanera. La autoridad que elabore el acta respectiva deberá entregar al interesado, en ese mismo acto, copia del acta de inicio del procedimiento, momento en el cual se considerará notificado. La autoridad aduanera procederá al embargo precautorio de la mercancía y al incio del PAMA en los casos referidos en el artículo 151 de la Ley Aduanera.

A través del reconocimiento aduanero, la verificación de mercancías en transporte o una comprobación se puede determinar las causas del embargo que prevé la propia Ley. Refiriéndonos a la secuencia que sigue el PAMA señalamos:

1. Inicio del procedimiento administrativo

2. En reconocimiento aduanero, verificación de mercancías en transporte o por el ejercicio de las facultades de comprobación

3. Se observa en la revisión de documentos presentados: El incumplimiento de regulaciones y restricciones no arancelarias

4. Se levanta el acta de inicio del procedimiento

5. Se embarga precautoriamente la mercancía y el medio de transporte queda en garantía

6. Se otorgan 10 días hábiles para ofrecer pruebas y alegatos

7. Si se refutan los hechos que dieron inicio al embargo precautorio, se dicta la resolución definitiva (absolutoria), no se aplican sanciones y se devuelven los bienes embargados

8. Cuando no se refutan los hechos que dieron inicio al embargo precautorio y se dicta la resolución definitiva en un plazo no mayor a 4 meses a partir del día posterior al día en que se integre el expediente (condenatoria) ${ }^{14}$, se fincan los bienes

\section{El procedimiento administrativo por contribuciones omitidas (PACO)}

El Procedimiento Administrativo por Contribuciones Omitidas (PACO) es aquel procedimiento para la determinación de las contibuciones y en donde la autoridad aduanera podrá resolver la imposición de un crédito fiscal si se detecta la omisión. En este tipo de procedimiento no procede el embargo precautorio de mercancías, como sucede en el PAMA, por tanto no ha lugar

\footnotetext{
13 México, Ley Aduanera (2019), artículo 150.

14 Ante esta resolución se podrán hacer valer los medios de defensa que correspondan. 
en el procedimiento administrativo por contribuciones omitidas, lo previsto en el artículo 151 de la Ley Aduanera, que establece los lineamientos para que las autoridades procedan al embargo precautorio de las mercancías y de los medios en los que se transportan. Este procedimiento aplica cuando procede la determinación de contribuciones omitidas, cuotas compensatorias y, dependiendo el caso, la imposición de sanciones.

Se realiza el procedimiento en los siguientes casos:

1. Cuando no se declare con exactitud la descripción o clasificación arancelaria de las mercancías y se omita el pago de las contribuciones y cuotas compensatorias

2. Cuando se invaliden los certificados de origen anexos a los pedimentos de importación

3. Cuando la mercancía sea de difícil identificación y/o requiera de toma de muestras

El acta de incio del procedimiento administrativo por contribuciones omitidas tiene lugar con motivo del ejercicio de las facultades de:

1. Reconocimiento aduanero

2. Segundo reconocimiento

3. Verificación de mercancías en transporte

4. Revisión de documentos durante el despacho

5. Ejercicio de las facultades de comprobación

Acto seguido, la autoridad aduanera dará a conocer los hechos que impliquen omisión de contribuciones, cuotas compensatorias y, en su caso, la imposición de sanciones. El artículo 144, fracción XV de la Ley Aduanera faculta a la Secretaría para determinar las contribuciones y aprovechamientos omitidos por los contribuyentes o responsables solidarios ${ }^{15}$. También la autoridad aduanera, en este momento, le hará saber al interesado que cuenta con un plazo de 10 días para ofrecer prueblas y formular los alegatos que le convengan. Los días que son consideraros dentro del plazo han de ser días hábiles.

Refiriéndonos a la secuencia que sigue el procedimiento administrativo por contribuciones omitidas señalamos:

1. Inicio del procedimiento administrativo

2. En reconocimiento aduanero, verificación de mercancías en transporte, revisión de los documentos presentados durante el despacho o del ejercicio de las facultades de comprobación

3. Se observa en la revisión de documentos presentados, la omisión de contribuciones y cuotas compensatorias

4. No se levanta el acta de incio del procedimiento (acta circunstanciada)

${ }^{15}$ México, Ley Aduanera (2019), artículo 144, fracción XV. 
5. No hay embargo precautorio

6. Se otorgan 10 días hábiles para ofrecer pruebas y alegatos

7. Si los hechos son refutados, no se determinan sanciones

8. Cuando no se refutan los hechos, se determinan las contribuciones y cuotas compensatorias omitidas y se imponen las sanciones

9. Se dicta la resolución definitiva en un plazo no mayor a 4 meses a partir del día posterior al día en que se integre el expediente

En el artículo 152 de la Ley Aduanera se prevé el proceso administrativo por contribuciones omitidas en los siguientes terminos:

En los casos en que con motivo del reconocimiento aduanero, de la verificación de mercancías en transporte, de la revisión de los documentos presentados durante el despacho o del ejercicio de las facultades de comprobación, en que proceda la determinación de contribuciones omitidas, aprovechamientos y, en su caso, la imposición de sanciones y no sea aplicable el artículo 151 de esta Ley, las autoridades aduaneras procederán a su determinación, sin necesidad de sustanciar el procedimiento establecido en el artículo 150 de esta Ley ${ }^{16}$.

El artículo 152 también dispone las actuaciones de la autoridad para la toma de muestras y señala que cuando se trate de mercancías de difícil identificación, que requiera la toma de muestras a fin de identificar su composición cualitativa o cuantitativa, uso, proceso de obtención o características físicas, se realizará dicha toma de acuerdo con el procedimiento que al efecto prevé el Reglamento de la Ley Aduanera, para su análisis y dictamen conducentes. Una vez obtenido el dictamen correspondiente, resultado del análisis practicado a las muestras de mercancías de difícil identificación, se notificarán al interesado mediante escrito o acta circunstanciada los hechos u omisiones advertidos, dentro de un plazo de 6 meses contados a partir del acta de toma de muestras correspondientes y se continuará el procedimiento conforme a lo establecido en ese artículo.

Cuando no se requiera la toma de muestras para su identificación y exista una incorrecta clasificación arancelaria, la autoridad aduanera dará a conocer mediante escrito o acta circunstanciada las cuestiones que impliquen la omisión de contribuciones, cuotas compensatorias y, en su caso, la imposición de sanciones.

Solo frente a estas circunstancias se le otorga el derecho de audiencia al posible infractor, cuando la mercancía requiere ser muestreada y del resultado de su análisis se adviertan omisiones, o cuando se trate de mercancías que no requieran ser muestreadas para su identificación y la autoridad señale que existe una incorrecta clasificación; se levantará un escrito o acta circunstanciada de las omisiones y se le señalará al interesado que cuenta con un plazo de 10

\footnotetext{
${ }^{16}$ México, Ley Aduanera (2019), artículo 152. 
días hábiles para ofrecer pruebas y alegatos y estos han de seguir los parametros previstos en el Código Fiscal Federal en los artículos 123 y 130.

Por su parte, a las autoridades se les otorga un plazo que no exceda de 4 meses a partir del día siguiente al que se encuentre debidamente integrado el expediente. En caso de omisión al cumplimiendo de dicho plazo habrá de poner a disposición del interesado su mercancía.

Una vez vencido los plazos para la presentación de todos los escritos de pruebas y alegatos es cuando se considera que el expediente se encuentra debidamente integrado, o en el supuesto de que la autoridad encargada de emitir la resolución haya llevado a cabo las diligencias necesarias para el desahogo de las pruebas ofrecidas por los promoventes. En los demás casos en que no proceda prueba en contrario, la determinación del crédito fiscal se hará por la autoridad aduanera.

Lo dispuesto en el artículo 152 no hace ningún señalamiento respecto a que la autoridad dé a conocer al interesado que los plazos para la presentación de documentos han vencido o que se han llevado las diligencias necesarias para el desahogo de las pruebas, dejando al interesado, con esta situación, imposibilitado para saber cuándo empieza a computar el plazo de los 4 meses en que ha de resolver la autoridad y que en caso de proceder se pondrá a inmediata disposición su mercancía.

En cuanto al domicilio que ha de registrársele al interesado para oír y recibir notificaciones, en términos del penúltimo párrafo del artículo 152 se prevé que:

En el escrito o acta de inicio del procedimiento se deberá requerir al interesado para que señale domicilio para oír y recibir notificaciones, apercibido que de no señalar el domicilio, de señalar uno que no le corresponda a él o a su representante, de desocupar el domicilio señalado sin aviso a la autoridad competente o señalando un nuevo domicilio que no le corresponda a él o a su representante, de desaparecer después de iniciadas las facultades de comprobación o de oponerse a las diligencias de notificación de los actos relacionados con el procedimiento, negándose a firmar las actas que al efecto se levanten, las notificaciones que fueren personales se efectuarán por estrados, siempre que, en este último caso y tratándose del reconocimiento aduanero, se cuente con visto bueno del administrador de la aduana ${ }^{17}$.

Siendo claro este párrafo en establecer cuándo se efectuarán las notificaciones por estrados. Por último, la disposición da lugar al supuesto que procede cuando hay imposición de sanciones sin la determinación de contribuciones o cuotas compensatorias omitidas o cuando no se embargan precautoriamente las mercancías, y dispone que la autoridad aduanera determinará el crédito fiscal sin necesidad de sustanciar el procedimiento administrativo por contribuciones omitidas o el PAMA, quedando a salvo sus derechos para interponer los medios de defensa. En este sentido, la autoridad aduanera emitirá y notificará el acto administrativo en el que se funde y motive la sanción aplicable.

Este último párrafo del artículo en comento faculta a la autoridad aduanera para determinar el crédito fiscal sin necesidad de substanciar los procedimientos establecidos en el artículo $150 \mathrm{y}$ 152 de la Ley y, bajo este supuesto, presupone que los derechos del contribuyente quedan a salvo mediante el recurso de revocación previsto en el Código Fiscal de la Federación. Optar por el 
recurso de revocación es un medio de impugnación posterior al procedimiento, el cual pudiera o no ejercer el contribuyente.

El contribuyente que lo interpone ya no está ejerciendo su derecho a una legítima defensa ante la propia autoridad que pretende sancionarlo por considerlo infractor. Ya queda librada la autoridad aduanera en tanto no ejerza el derecho de defensa el contribuyente y acuda al recurso. Son muchos los supuestos dentro de la Ley Aduanera en los que las autoridades aduaneras se encuentran facultados para determinar el crédito fiscal sin necesidad de llevar a cabo ningún procedimiento $^{18}$. Sin embargo, por no configurarse en estos supuestos la omisión de contribuciones ni de cuotas compensatorias, ni ser aplicable el embargo precautorio de mercancías, no se da origen a un procedimiento en el cual el interesado pueda acudir a defenderse contra un acto de autoridad que concluye en la determinación de un crédito fiscal.

Aclarado lo anterior, cabe resaltar que la Ley Aduanera no reconoce en los párrafos citados la intervención del sujeto afectado, esto no permite que sea desarrollado un procedimiento conforme al debido proceso, negando y violando los derechos humanos, dejándole en un estado de indefensión frente a los actos de autoridad aduanera, siendo improcedente la participación de éste y la oportunidad de que ofrezca prueba en contrario para intentar refutar y defenderse frente al acto que pretende modificar su esfera de derechos.

Para que pudiese existir el ejercicio del derecho al debido proceso es necesario que se vean cubiertos los parámetros mínimos establecidos constitucionalmente, también previstos por la doctrina y por los ordenamientos internacionales así como las prerrogativas básicas de desarrollo del proceso legal y la necesaria observancia de dichos parámetros en pro de un respeto total de los derechos humanos, fundamentalmente, de la audiencia previa de los sujetos afectados por los actos de autoridad aduanera.

De primera instancia, nos parecieran simples omisiones de la autoridad que no tienen mayor relevancia, pero, al analizarlos con detenimiento, caemos en cuenta que se trata de pautas dadas por nuestra Constitución, la doctrina y mecanismos internacionales que son violadas sistemáticamente.

\section{El debido proceso}

Las necesidades de una población y la evolución de sus instituciones es lo que da lugar al reconocimiento y otorgamiento de un derecho. El reconocimiento del derecho al debido proceso es el resultado de un camino recorrido por la humanidad que se ha visto en la necesidad de hacer frente a los atropellos dentro de los procesos, la vulneración de derechos humanos y las afectaciones graves que se han hecho a la esfera jurídica de los seres humanos cuando se encuentran en calidad de gobernados.

Desde una visión histórica, el debido proceso ya era contemplado como una institución en el derecho inglés desde antes de su implementación en América, en donde a su llegada lo instauraron como la institución del debido proceso, como lo señala al respecto Linares:

En el momento de su trasplante a las colonias tenía las dos siguientes características: a) Era una mera garantía procesal de la libertad personal contra las detenciones arbitrarias del estado, y accidentalmente contra las penas pecuniarias y confiscaciones, es decir, contra penas sin juicio legal por los pares. No obstante, debe reconocerse que ya en las Institutas de Coke había anticipos claros de la posibilidad de que pudiera constituir una garantía contra la aplicación

\footnotetext{
${ }_{18}$ Véase del artículo 180 al 192 de la Ley Aduanera. 
injusta de las normas del common law o aún de los estatutos. b) El Debido proceso ofrecía garantías contra la arbitrariedad del monarca o jueces, pero no del Parlamento ${ }^{19}$.

Es así como esta tendencia a la observancia de lineamientos mínimos trasciende en los ordenamientos jurídicos de nueva creación en el continente. Así mismo en 1866 Estados Unidos convirtió el debido proceso en parte de la enmienda $\mathrm{XIV}^{20}$.

En el sistema jurídico de los Estados Unidos, tenemos que la Corte Federal ha consignado el concepto de debido proceso al menos en dos garantías mínimas:

a) Due process procesal, que significa que ningún órgano jurisdiccional puede privar a las personas de la vida, libertad o propiedad, a excepción que tenga la oportunidad de alegar y ser oída, $y$ b) Due process sustantivo, que quiere decir que el gobierno no puede limitar o privar arbitrariamente a los individuos de ciertos derechos fundamentales contenidos en la Constitución. De esta forma se crea un poder de control sobre la discrecionalidad administrativa ${ }^{21}$.

Una constante asimilación del concepto implica su paso de una etapa histórica a otra, para Cipriano Gómez Lara, el resultado del proceso evolutivo para el reconocimiento de la garantía del debido proceso en el siglo XX se resume en: a) la constitucionalización de las garantías procesales y b) la protección de estas mismas garantías o derechos en instrumentos internacionales ${ }^{22}$. Para este mismo autor el proceso es un instrumento para solucionar ciertos tipos de conflictiva social... el cual permite el mantenimiento de ese equilibrio de las relaciones jurídicas contrapuestas $^{23}$. Desde esta perspectiva, el proceso es como un instrumento que fija las reglas básicas a seguir que por orden constitucional no deben contraponerse ni violentar de forma alguna los derechos humanos.

José Ovalle Favela señala que Derecho Procesal es el conjunto de normas y principios jurídicos que regulan tanto el proceso jurisdiccional como la integración y competencia de los órganos del Estado que intervienen en el mismo ${ }^{24}$. En ese mismo sentido, diferentes ordenamientos internacionales hacen un reconocimiento expreso del respeto a los Derechos que protegen a las personas involucradas en un proceso legal. La Corte Interamericana de Derechos Humanos, en el caso Genie Lacayo párrafo 74, define al debido proceso como el derecho de toda persona a ser oída con las debidas garantías y dentro de un plazo razonable por un juez o tribunal competente, independiente e imparcial, establecido con anterioridad por la ley, en la sustanciación de

\footnotetext{
${ }^{19} \mathrm{Al}$ referirse en el inciso A, a las penas sin juicio legal por los pares, era en relación con ser juzgado por tu igual, debido a la jerarquía clasista, se refiere a ser juzgado por alguien del mismo estatus económico y social. Véase, LinAREs, Juan Francisco (1989), La razonabilidad de las leyes, Argentina, 2da ed., Astrea , p. 16. ${ }^{20}$ Idem

${ }^{21}$ Gozaíni, Osvaldo Alfredo (2011), El Debido proceso Constitucional. Reglas para el Control de los Poderes Desde la Magistratura Constitucional, Instituto de Investigaciones Jurídicas de la Universidad Autónoma de México, [en línea], disponible en: http://www.juridicas.unam.mx/publica/rev/cconst/cont/7/ard/ard2.htm (consultado el 10 de diciembre de 2018).

${ }^{22}$ Gómez Lara, Cipriano (2006), El debido proceso como Derecho Humano, Centro de investigaciones jurídicas de la UNAM, p. 342, [en línea], disponible en: http://biblio.juridicas.unam.mx/libros/4/1968/17.pdf (consultado el 12 de diciembre de 2018)

${ }^{23}$ Gómez Lara, Cipriano (1990), Teoría General del Proceso, 8a ed., México, Universidad Autónoma de México, Harla, p. 2.

${ }^{24}$ Ovalle Favela, José (2005), Teoría General del Proceso, México, 6ta ed., Universidad Autónoma de México, Oxford, p. 39.
} 
cualquier acusación penal formulada en su contra o para la determinación de sus derechos de carácter civil, laboral, fiscal u otro cualquiera ${ }^{25}$.

Lo anterior de conformidad con el artículo $8^{\circ}$, fracción I, sobre Garantías Judiciales de la Convención Americana sobre Derechos Humanos. Dentro del mencionado artículo expresamente se establece las siguientes prerrogativas básicas de garantía del individuo con respecto del proceso:

Toda persona tiene derecho a ser oída, con las debidas garantías y dentro de un plazo razonable, por un juez o tribunal competente, independiente e imparcial, establecido con anterioridad por la ley, en la sustanciación de cualquier acusación penal formulada contra ella, o para la determinación de sus derechos y obligaciones de orden civil, laboral, fiscal o de cualquier otro carácter ${ }^{26}$.

Estableciendo en las siguientes fracciones del artículo 8, las garantías mínimas que han de seguirse en un procedimiento, entre éstas: la presunción de inocencia, traductor o intérprete gratuito, previo conocimiento de la acusación formulada, preparación de su defensa, defenderse personalmente o por un defensor particular o proporcionado por el Estado, tener testigos, derecho a no declararse culpable, a recurrir el fallo, confesión sin coacción, no tener otro juicio por los mismos hechos, proceso penal público ${ }^{27}$.

De igual forma es contemplado este precepto básico y su concepto en uno de los ordenamientos más importantes a nivel mundial, La Declaración Universal de Derechos Humanos, previendo en el artículo 10 que:

Toda persona tiene derecho, en condiciones de plena igualdad, a ser oída públicamente y con justicia por un tribunal independiente e imparcial, para la determinación de sus derechos $y$ obligaciones o para el examen de cualquier acusación contra ella en materia penal ${ }^{28}$.

Y disponiendo la Declaración Universal de Derechos Humanos en su artículo 11, en la fracción I, el derecho a la presunción de inocencia, al juicio público y a la defensa, y en la fracción II, el derecho a no ser condenado por actos u omisiones que en el momento de cometerse no fueron delictivos según el derecho nacional o internacional, o a que se le imponga pena más grave que la aplicable en el momento de la comisión del delito ${ }^{29}$.

Por su parte, en nuestro propio sistema jurídico y revisando lo que la Corte ha dicho al respecto, podemos ver que dentro de la fuente jurisprudencial a nivel nacional, si se busca en el ya mencionado Sistema de Tesis y Jurisprudencias de la SCJN denominado IUS, la palabra debido proceso, el resultado arrojado es de 490 elementos solo de la novena y décima época. Queda con eso un poco más claro que ha sido un tema recurrente y de peso en nuestro sistema jurisdiccional.

La SCJN en la tesis de jurisprudencia 11/2014 establece las garantías del debido proceso que aplican a cualquier procedimiento de naturaleza jurisdiccional son las que esta SCJN ha identificado como formalidades esenciales del procedimiento, cuyo conjunto integra la "garantía de

\footnotetext{
${ }^{25}$ Corte Interamericana de Derechos Humanos (1997), Costa Rica, 29 de enero, [en línea], disponible en: http:// www.corteidh.or.cr/docs/casos/articulos/seriec_30_esp.pdf (consultado el 10 de octubre de 2018)

${ }^{26}$ Convención Americana sobre Derechos Humanos (1978), Artículo 8, fracción 1.

${ }^{27}$ Ibídem, Artículo 8, fracciones II - V.

${ }^{28}$ Declaración Universal de Derechos Humanos (1948), artículos 10.

${ }^{29}$ Ibídem, Artículo 11, fracciones I y II. 
audiencia", las cuales permiten que los gobernados ejerzan sus defensas antes de que las autoridades modifiquen su esfera jurídica definitivamente ${ }^{30}$.

Siendo esta jurisprudencia obligatoria desde el o3 de marzo de 2014, define también dichas formalidades esenciales del procedimiento, esto es para un desarrollo de la actuación de la autoridad conforme al debido proceso. Dejando claro que el debido proceso no es un concepto de reciente creación, sino que ha sido reconocida su tutela como una necesidad del individuo para protección de la persona ante las actuaciones de la autoridad.

En nuestro país, el organismo denominado Comisión Nacional de los Derechos Humanos $(\mathrm{CNDH})$ define al debido proceso como el derecho que tiene toda persona para ejercer su defensa y ser oída, con las debidas oportunidades y dentro de un plazo razonable, por la autoridad competente previo al reconocimiento o restricción de sus derechos y obligaciones ${ }^{31}$. Además establece como requisitos mínimos que contenga las siguientes garantías:

I. El aviso de inicio del procedimiento;

II. La oportunidad de ofrecer pruebas y alegar;

III. Una resolución que resuelva las cuestiones debatidas; y

IV. La posibilidad de reclamar la resolución mediante un recurso eficaz ${ }^{32}$.

De tal forma entendemos que el debido proceso es una prerrogativa básica que debe ser de observancia general, respetada, promovida y vigilada su aplicación, como Derecho Humano contemplado en nuestra Constitución, que contiene el fundamento del derecho a un debido proceso en el artículo 14, estableciendo que:

A ninguna ley se dará efecto retroactivo en perjuicio de persona alguna. Nadie podrá ser privado de la libertad o de sus propiedades, posesiones o derechos, sino mediante juicio seguido ante los tribunales previamente establecidos, en el que se cumplan las formalidades esenciales del procedimiento y conforme a las Leyes expedidas con anterioridad al hecho ${ }^{33}$.

Mientras que el artículo 16 de la Constitución establece que:

Nadie puede ser molestado en su persona, familia, domicilio, papeles o posesiones, sino en virtud de mandamiento escrito de la autoridad competente, que funde y motive la causa legal del procedimiento ${ }^{34}$.

En los lineamientos constitucionales, tal como en los ordenamientos citados con anterioridad, se reconocen principios básicos para el desarrollo de un proceso sin violentar los derechos

\footnotetext{
${ }^{30}$ Tesis $1^{a} / J .11 / 2014$, Semanario judicial de la federación y su gaceta, Décima Época, t. I, febrero de 2014, p.396, [en línea], disponible en: https://sjf.scjn.gob.mx/sjfsist/Paginas/DetalleGeneralV2.aspx? ID=2005716\&Clase=Detalle TesisBL (consultado el 20 de octubre de 2018)

${ }^{31}$ Comisión Nacional de los Derechos Humanos, Debido proceso, México, [en línea], disponible en: http://www. cndh.org.mx/Derecho_Audiencia_Proceso_Legal (consultado el 2 de noviembre de 2018)

${ }^{32}$ Idem.

${ }^{33}$ Constitución Política de los Estados Unidos Mexicanos (1917), Artículo 14.

34 Ibídem, artículo 16.
} 
humanos de la persona sujeta a éste y, sobre todo, el hecho de que a nadie, ninguna autoridad, le puede modificar su esfera jurídica sin que previamente el gobernado ejerza su defensa ante esta.

La anterior puntualización sirve para dar claridad de los criterios considerados dentro de este derecho humano, tanto lo establecido por la Corte Interamericana en el Pacto de San José, así como en un instrumento tan importante como lo es la Declaración Universal de los Derechos Humanos, para continuar hasta nuestra Carta Magna, pasando así a la CNDH, otorgando y reconociendo pautas básicas del desarrollo de un procedimiento apegado a derechos humanos para protección y certeza jurídica del gobernado respecto del actuar de la autoridad, vigilando la observancia de estos preceptos mínimos de protección de los derechos de los individuos.

Sin embargo, al analizar todo lo anterior, surge una duda, ¿en verdad se respetan estas prerrogativas básicas de protección del gobernado contra actos de autoridad, o son simplemente un reconocimiento positivizado de un derecho al que fácticamente todos vulneran de manera reiterada?

\section{Protección internacional al debido proceso}

A nivel internacional, encontramos una serie de instrumentos tanto no vinculantes como vinculantes que refieren una obligación directa a cargo de las autoridades que se encuentran dentro de un Estado parte. Las autoridades en todos los niveles de gobierno tienen la obligación de respetar, proteger, promover y garantizar los derechos humanos y las libertades fundamentales de las personas sin distinción alguna. Con relación al derecho humano al debido proceso, encontramos instrumentos tanto universales como regionales que lo protegen:

Instrumentos internacionales de carácter universal:

- Declaración Universal de los Derechos Humanos, dispone que toda persona tiene derecho a un recurso efectivo que se lleve a cabo ante los tribunales competentes que la proteja contra actos que violen sus derechos ${ }^{35}$. Asimismo, establece que tienen derecho a ser oídos públicamente y con justicia ante un tribunal imparcial ${ }^{36}$.

- Pacto Internacional de Derechos Civiles y Políticos, suscrito el 16 de diciembre de 1966, entró en vigor el 23 de marzo de 1976, hasta la fecha ha sido ratificada por 172 países de los cuales, México la ratifico el 20 de mayo de 1981. Establece que es un derecho humano de toda persona (que el Estado deberá garantizar) la interposición de un recurso efectivo por la violación de esos derechos o libertades ante autoridad competente, quien decidirá sobre sus derechos ${ }^{37}$.

Instrumentos internacionales de carácter regional:

- Declaración Americana de los Derechos y Deberes del Hombre, señala que toda persona tiene el derecho de acudir ante los tribunales para hacer valer sus derechos mediante un procedimiento sencillo y breve contra actos de autoridad que violen sus derechos fundamentales ${ }^{38}$.

\footnotetext{
35 Declaración Universal de los Derechos Humanos (1948), artículo 8.

${ }^{36}$ Ibídem, artículo 10.

37 Pacto Internacional de Derechos Civiles y Políticos (1976), artículo 2.3.

${ }^{38}$ Declaración Americana de los Derechos y Deberes del Hombre (1948), artículo XVIII. 
- Convención Americana sobre Derechos Humanos (Pacto de San José), suscrita el 22 de noviembre de 1969, entró en vigor el 18 de julio de 1978, hasta la fecha ha sido ratificada por 25 países de los cuales, México la ratifico el 02 de marzo de 1981. Dicha Convención dispone que toda persona tiene derecho a ser oída dentro de un plazo razonable y ante un tribunal competente establecido con anterioridad por la ley ${ }^{39}$, que la proteja contra actos que violen sus derechos fundamentales, dicho procedimiento deberá ser sencillo y rápido ${ }^{40}$.

A continuación se muestra una tabla en donde se observan dichos instrumentos de conformidad con la división que se hace con base en su tipología, es decir, en razón de su obligatoriedad; en razón del área geográfica y; en razón de los sujetos a quienes va dirigido:

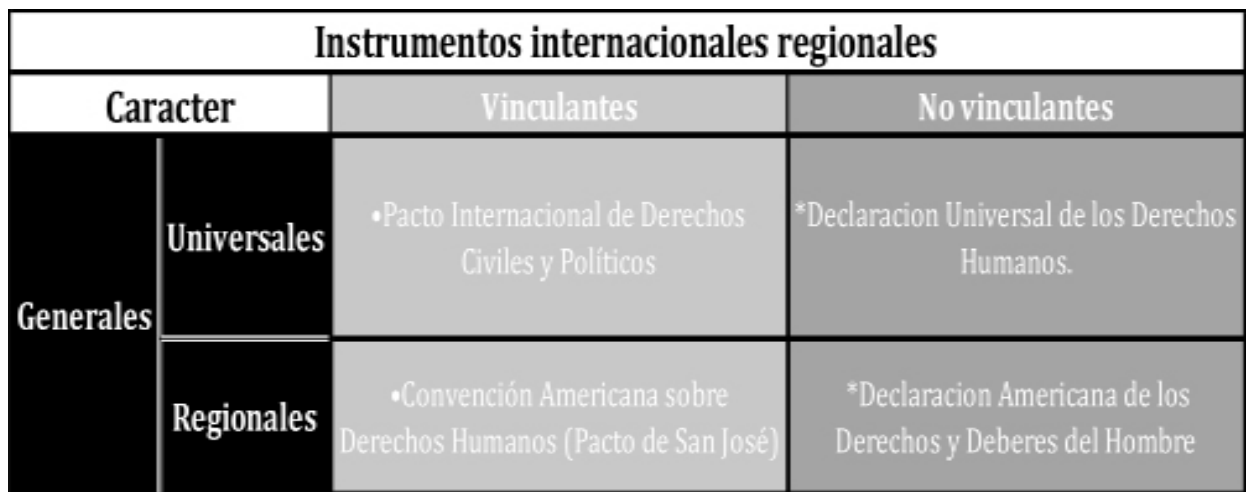

Tabla 1. Instrumentos internacionales que prevén el debido proceso. Elaboración propia.

Dentro de la Tabla 1 se muestran aquellos instrumentos internacionales que contemplan el derecho humano al debido proceso. Dichos instrumentos son de carácter general pues van dirigidos a proteger los derechos humanos de todas las personas, dentro de los cuales encontramos dos (las Declaraciones) de carácter no vinculante, esto es, no son obligatorias para los Estados parte, por tal motivo, se suscribieron tanto el Pacto como la Convención, es decir, para dar fuerza vinculante a los derechos consagrados en las declaraciones.

Como se pudo observar dentro del presente apartado realizamos una relación de los intrumentos internacionales que proteguen el derecho al debido proceso y respecto a los cuales nos encontramos obligados a velar por su cumplimiento con Estado parte.

\section{Conclusiones}

Luego del análisis hecho alrededor de la problemática que representa el colocar al gobernado en un estado de indefensión e incertidumbre jurídica con respecto del actuar de la autoridad -violando su derecho al debido proceso-, sin dejar de lado el hecho de que éste es un derecho humano reconocido y otorgado por un gran número de instrumentos internacionales en los que se establecen las pautas básicas de desarrollo de un proceso a manera de protección del individuo, observamos que estos mismos preceptos son reconocidos también por nuestra Constitución a través de prerrogativas mínimas que se conceden al individuo para su protección contra los actos de autoridad de afectación directa sobre la esfera jurídica del gobernado. Está

\footnotetext{
${ }^{39}$ Convención Americana de los Derechos Humanos (1978), artículo 8.

${ }^{40}$ Ibídem, artículo 25.
} 
reconocido el debido proceso por la Organización de las Naciones Unidas, la Unión de Estados Americanos, la Suprema Corte de Justicia de la Nación, la Comisión Nacional de los Derechos Humanos y por nuestra propia Constitución, que lo dispone como un derecho humano de observancia general y establece las pautas mínimas en las que debe llevarse un proceso para no ser violatorio. Podemos afirmar como consecuencia del presente estudio, que todos los ordenamientos anteriormente citados, que marcan las prerrogativas básicas para el desarrollo de los procedimientos conforme a derecho, no son respetadas en algunos de los procedimientos que se llevan a cabo en materia aduanera, como es el caso del procedimiento administrativo por contribuciones omitidas.

Pero además, es preciso señalar que las violaciones son sistemáticamente reiteradas por la autoridad aduanera que, en el ejercicio de sus funciones no delimitadas de forma exacta y dejando lagunas para que la autoridad tenga que aplicar su facultad discrecional -lo que de por sí ya representa una violación al principio de legalidad-, dispone que los poderes públicos están sujetos a la ley ${ }^{41}$.

Son esas facultades tan extensas que no permiten que la autoridad aduanera se apegue a un un debido proceso, además de estar facultados por diversos ordenamientos que van más allá de lo dispuesto en nuestra Constitución, lo que provoca violaciones a los derechos humanos del contribuyente, dejándolo en un estado de indefensión con respecto a los actos de autoridad que pretenden modificar sus derechos, creando incertidumbre en el gobernado sobre el actuar de las autoridades aduaneras respecto de sus facultades y limitaciones, lo que coloca al gobernado en una situación de notoria desventaja jurídica en relación con la autoridad, ya que, al verse superada, crea brechas para suplir las lagunas que se presentan, violentando primeramente su obligación de hacer solo lo que la ley le permite, para después transgredir los derechos del gobernado.

El derecho es creado para la sociedad a la cual va dirigido y surge de la necesidad de regular conductas. Por tanto, es necesario la reformulación o aclaración y delimitación de los procedimientos aduaneros, en el tema que nos ocupa, la delimitación del procedimiento administrativo por contribuciones omitidas, que da lugar a que las autoridades se extralimiten por la falta de determinación clara y precisa de sus facultades y vulneren derechos humanos.

El crecimiento económico debería ser uno de los objetivos primordiales y los ordenamientos tanto fiscales como aduaneros, deberían de favorecer al sector privado para el fortalecimiento del comercio exterior, la propuesta de Adam Smith para el correcto funcionamiento de una economía de mercado es que el Estado debe regular e intervenir para garantizar el acceso a todos los agentes económicos a los mecanismos de mercado, posibilitando una economía de mercado abierta a todos los hombres ${ }^{42}$.

Sin embargo, actualmente, esto no se ha visto reflejado y, por el contrario, vemos que tal incompatibilidad del ordenamiento aduanero con los instrumentos internacionales de derechos humanos, solo ha reportado un descenso económico. El comportamiento de las empresas ha cambiado paulatinamente, un número mayor de éstas realizan actividades de carácter interna-

\footnotetext{
${ }^{41}$ Guastini, Ricardo (2001), Estudios de Teoría Constitucional, Traducción de Miguel Carbonell, con la colaboración de Karla Pérez Portilla, México, UNAM, Instituto de Investigaciones Jurídicas, p.124.

42 Smith, Adam (1794), Investigación de la naturaleza y causa de la riqueza de las naciones, Libro I. Cap. X. Parte II. Desigualdades que produce la política de Europa, Sección I, traducción de José Alonso Ortiz, España, Oficina de la viuda e Hijos de Santander, pp. 203-207.
} 
cional, pero esto no ha repercutido en que las empresas mexicanas tengan una sólida presencia en la escena internacional ${ }^{43}$.

Nuestra Constitución y los instrumentos internacionales de derechos humanos tienen jerarquía sobre la Ley Aduanera, que es un ordenamiento secundario dentro de nuestro sistema jurídico, y nunca un ordenamiento secundario puede limitar o reducir un derecho humano establecido, siendo obligación de las autoridades en cualquier nivel de gobierno el velar por el respeto, promoción y protección de los derechos humanos.

\section{Fuentes}

\section{Libros}

Aguado Romero, Gabriela, et al. (2016), Derecho administrativo. Un ámbito para el respeto, promoción, protección y garantía de los derechos humanos, México, Tirant lo Blanch.

Bello, Nohemí y Avendaño, Luis (2015), "La garantía de audiencia en algunos procedimientos aduaneros”, Letras Jurídicas, Veracruz - México, Año 16, No. 31, enero - junio 2015.

Cancino, Rodolfo y Askar, Rubén Abdo (2017), El Procedimiento Administrativo en Materia Aduanera. Teoria y Práctica, México, Universidad Tecnológica de Ciudad Juárez.

FILLIS, Ian (2001), "Small firm Internationalisation: an investigative survey and future research directions”, Scotland, Journal of Management Decision, Vol. 39, Issue 9.

Gómez Lara, Cipriano (1990), Teoría General del Proceso, 8a ed., México, Universidad Autónoma de México, Harla.

Gómez Lara, Cipriano (2006), El debido proceso como Derecho Humano, Centro de investigaciones jurídicas de la UNAM, [en línea], disponible en: http://biblio.juridicas.unam.mx/ libros/4/1968/17.pdf (consultado el 12 de diciembre de 2018)

Gozaíni, Osvaldo Alfredo (2011), El Debido proceso Constitucional. Reglas para el Control de los Poderes Desde la Magistratura Constitucional, Instituto de Investigaciones Jurídicas de la Universidad Autónoma de México, [en línea], disponible en: http://www.juridicas.unam.mx/publica/rev/cconst/cont/7/ard/ard2.htm (consultado el 10 de diciembre de 2018)

Guastini, Ricardo (2001), Estudios de Teoría Constitucional, Traducción de Miguel Carbonell, con la colaboración de Karla Pérez Portilla, México, UNAM, Instituto de Investigaciones Jurídicas.

Grupoei (2019), Proceso y tipos de reconocimiento aduanero, 4 de diciembre de 2019, [en línea], disponible en: https://blog.grupoei.com.mx/proceso-reconocimiento-aduanero (consultado el 24 de junio de 2019)

Hoyos, Arturo (2006), Debido proceso y democracia, México, Porrúa.

43 FILlis, Ian (2001), "Small firm Internationalisation: an investigative survey and future research directions", Scotland, Journal of Management Decision, Vol. 39, Issue 9, p. 767- 783. 
Linares, Juan Francisco (1989), La razonabilidad de las leyes, Argentina, 2da ed., Astrea.

Ovalle Favela, José (2005), Teoría General del Proceso, México, 6ta ed., Universidad Autónoma de México, Oxford.

Rivera Ruiz, Libertad (2019), “Documento de Operación para Despacho Aduanero (DODA)”, Revista Eje de Comercio Exterior. Aduanas, México, [en línea], disponible en: http:// aduanasrevista.mx/documento-de-operacion-para-despacho-aduanero-doda/ (consultado el 24 de junio de 2019)

Smith, Adam (1794), Investigación de la naturaleza y causa de la riqueza de las naciones, Libro I. Cap. X. Parte II. Desigualdades que produce la política de Europa, Sección I, traducción de José Alonso Ortiz, España, Oficina de la viuda e Hijos de Santander.

\section{Legislación Nacional}

México, Constitución Política de los Estados Unidos Mexicanos (2019), artículos 14 y 16.

México, Ley Aduanera (2018), Artículos 43, 46, 144, fracciones XI y XV, 150, 152, 180 y 192.

México, Reglamento de la ley aduanera

Comisión Nacional de los Derechos Humanos, Debido proceso, México, [en línea], disponible en: http://www.cndh.org.mx/Derecho_Audiencia_Proceso_Legal (consultado el 2 de noviembre de 2018)

\section{Jurisprudencia}

Tesis $1^{a} / J .11 / 2014$, Semanario judicial de la federación y su gaceta, Décima Época, t. I, febrero de 2014, p.396, [en línea], disponible en: https:/sjf.scjn.gob.mx/sjfsist/Paginas/DetalleGeneralV2.aspx?Clase $=$ DetalleTesisBL $\& I D=2005716 \&$ Semanario $=0 \quad$ (consultado el 20 de octubre de 2018)

195466. XIV.20.38 A. Tribunales Colegiados de Circuito. Novena Época. Semanario Judicial de la Federación y su Gaceta. Tomo VIII, Octubre de 1998, Pág. 1179.

\section{Instrumentos internacionales}

Convención Americana de los Derechos Humanos (1978), Artículo 8, fraciones I-V y Artículo 25.

Corte Interamericana de Derechos Humanos (1997), Costa Rica, 29 de enero, [en línea], disponible en: http://www.corteidh.or.cr/docs/casos/articulos/seriec_30_esp.pdf (consultado el 10 de octubre de 2018)

Declaración Universal de los Derechos Humanos (1948), artículo 8,10 y 11, fracciones I y II.

Declaración Americana de los Derechos y Deberes del Hombre (1948), artículo XVIII. 
Pacto Internacional de Derechos Civiles y Políticos (1976), artículo 2.3. 